\title{
REVIEW
}

\section{Phonetics for Phonics}

\author{
A Review by ROSS FORMAN
}

\section{PHONETICS FOR PHONICS: UNDERPINNING KNOWLEDGE FOR ADULT LITERAGY PRACTITIONERS BY MAXINE BURTON}

National Institute of Adult and Continuing Education (NIACE), 2011, Leicester, UK ISBN: 978-1-86201-453-4, 70 pages, http://www.niace.org.uk/

This is a slim volume of 70 pages, relating to the UK context, which represents an interesting and valuable resource for adult literacy practitioners.

Debate over the relative merits of the two principal approaches to reading - Phonics and Whole Language - emerges from time to time. Such debate is often initiated by a Phonics camp, and gets the support of the popular press, the latter which rarely lets logic get in the way of a good story. But certainly teachers of reading at primary school in Australia, for many years now, have drawn upon both approaches: integrating a focus on sounds, letters and words with reading as a social activity which is purposeful and meaning-oriented.

The early chapters of this welcome book justify a role for phonics hitherto neglected - in the teaching of adult literacy. I believe that if we consider what can be reasonably expected of a literacy teacher, 'language awareness' must be one key quality. That is, awareness of how language (in this case, English) works: how it sounds (phonology), and looks (graphology), to both native-speaking and second-language students. As the author points out, without an understanding of phonics, literacy teachers may provide less-than-helpful, or even incorrect guidance to their students.

One of the big issues, however, is the place of phonics within literacy teaching. While the author affirms that phonics should occur within 'a broad and rich literacy curriculum' (p. 7), later in the volume she asserts that indeed phonics should be the 'first port of call' (p. 37). This is a view which differs from my own, and probably from the views of most adult literacy practitioners and researchers. 
We are provided in Chapter 3 with a brief explanation of the International Phonetic Alphabet (IPA), as a lead-in to Chapter 4, which outlines the basis of phonetics. This complex area is not easy to explain, and the author has done a fine job of describing the sounds and symbols of English. This is essential knowledge for teachers of English literacy. My only suggestion here would be to clarify the presentation. In order to exemplify groups of phonemes, I would recommend new line, indent, and bullet points (rather than treating these as undifferentiated text); and the use of tables/charts wherever possible. For example, the grouping of consonant and vowel sounds could be based on the IPA chart itself, or upon schemes commonly used in ESL teaching, such as Underhill (2005).

Chapter 5 examines the UK's Adult Literacy Core Curriculum guidelines for writing, and offers careful critique of various parts of that document. As such, this part is probably of greater interest to curriculum writers and teacher-educators. But Chapter 6 includes many excellent points for practitioners, such as the care needed in order to 'sound out' words correctly.

Chapter 7 presents a thoughtful and accurate explanation of 'accent', taken here to mean regional or social variation of pronunciation. The author claims that such variation does not jeopardise phonics teaching. Fair enough - but I feel that in the face of phonetic variation, the complementary cueing systems of meaning (semantics) and grammar (syntax/morphology) are bound to take on greater significance.

The Glossary is excellent; the Appendices are clearly set out and of great value as resources and references. In Appendix 1, Table 2 on p. 56, there appears to be a mistake in the Letters \& Sounds representation of the word 'air'. I was glad to see the author's objection to the UK Core Curriculum's invention of two additional and unnecessary short-vowel phonemes (p. 61, note 2).

Finally, we need to consider how accessible is this book to an individual reader. To her credit, the author has included a number of doable tasks, and supplemented these with links to additional resources. The Appendices alone would justify this book's presence on any literacy teacher's desk. Nevertheless, without having previously studied some phonetics, I believe that most readers would require additional mediation/support in order to fully grasp and apply the wisdom contained herein. For this reason, I suggest that the book may best serve practitioners either as a source of reference, and/or as a basis for professional development sessions.

\section{References}

Underhill, A (2005) Sound Foundations $2^{\text {nd }}$ edn, MacMillan, Oxford. 